\title{
INFLUENCE OF MATHEMATICS BRAILLE PROFICIENCY ON MATHEMATICS PERFORMANCE AMONG LEARNERS WITH VISUAL IMPAIRMENT IN SELECTED SPECIAL SECONDARY SCHOOLS IN KENYA
}

\author{
Martin Obiero Okumu1i, \\ Margaret W. Murugami², \\ Lubna M. Mazrui ${ }^{3}$ \\ ${ }^{1}$ Head of Department, \\ Public Information Services, \\ Kenya Institute for the Blind, \\ Kenya \\ ${ }^{2}$ Dr., Senior Lecturer, \\ Department of Early Childhood and \\ Special Needs Education, \\ Specialization: Visual Impairment, \\ and Inclusive Education, \\ Kenyatta University, \\ Kenya \\ ${ }^{3}$ Dr., Lecturer, \\ Department of Early Childhood and \\ Special Needs Education, \\ Specialization: Visual Impairment, \\ Kenyatta University, \\ Kenya
}

\begin{abstract}
:
The purpose of this paper is to report some of the findings of a study which investigated the influence of mathematics Braille proficiency on mathematics performance among learners with visual impairment in selected special secondary schools in Kenya. In this study, descriptive design was used with a sample size of 55 respondents comprising of head teachers, mathematics teachers and learners with visual impairment in two special secondary schools. The study respondents were purposively sampled. Findings on the level of mathematics braille proficiency possessed by learners with visual impairment; and the relationship between mathematics Braille skills and mathematics performance are reported. These findings demonstrate a very low level of mathematics Braille skills; and there was a significant positive relationship between mathematics braille proficiency and mathematics performance, particularly among touch readers. These findings
\end{abstract}

i Correspondence: email obikumu@gmail.com 
confirmed that lack of mathematics braille proficiency contributed to poor mathematics performance. On the basis of these findings, some recommendations are provided.

Keywords: mathematics Braille proficiency, learners with visual impairment, mathematics performance

\section{Introduction}

Learners who are visually impaired should learn mathematics just like their sighted counterparts. This is because being competent in mathematics enhances educational and occupational opportunities for all. Workplaces require advanced computational and technological skills. Those who do not possess the skills are restricted in career choices (Kapperman, Heinze \& Sticken, 2002). Thus, good performance in mathematics has an overall bearing on an individual's academic performance and employability in various sectors of a country's economic development. This is partly why mathematics is a compulsory subject for all primary and secondary school learners in Kenya.

Despite the importance of mathematical skills for educational and occupational success, acquisition of mathematical skills can be more difficult for students with visual impairment due to the abstract nature of many essential concepts and highly visual presentation of the subject. In addition, learners with visual impairments are known to have challenges related to strategies used by their teachers to deliver mathematical concepts (Kapperman, Heinze \& Sticken, 2000). In addition, inadequacies in instructional materials as well as learners' negative attitude towards the subject are factors which affect the performance of LWVI in mathematics (Wadnor, 2013).

Despite numerous challenges faced by learners with visual impairments (LWVI), famous mathematicians who were blind are recorded in history. These include: Michael Sanderson, a lecturer in statistics, Bernard-Morin and Emmanuel Girox, who were experts in geometry, and Lawrence Baggett who was a lecturer in analysis (Jackson, 2002). Nemeth, (1988), a person with a visual impairment in the US was also known for developing a Mathematical code that is still in use to date. These historical accounts demonstrate that persons with visual impairment can acquire mathematical skills and even become experts in mathematics if they are provided with appropriate educational experiences.

For many years, performance in mathematics for LWVI in Kenya has been generally poor (KNEC, 2005). This may be due to several factors (SMASE, 1988). The study whose findings are reported in this paper sought to investigate the possible contribution of one of these factors on the mathematics performance of learners with visual impairment: these learners' mathematics Braille proficiency.

Although much research has been done in the area of Braille, a lot more remains unknown about mathematics Braille notation which is the medium learners with visual impairment use to learn mathematics. Research done by Nzoka (2011), Mangula (2010), Mwangi (2014) and Njue (2009) have either concentrated their studies at the primary level 
or looked at Braille competency in general, without looking at different Braille codes that could adversely affect learning of different subjects. Hence this study focused on Maths Braille proficiency and its influence on mathematics performance at the secondary school level. Findings on the level of mathematics braille proficiency possessed by learners with visual impairment; and the relationship between mathematics Braille skills and mathematics performance are reported.

\section{Methodology}

The findings reported in this paper were obtained from a study which employed a descriptive design. This design enabled the provision of detailed information from the research participants because its sole purpose is to describe a behavior or type of subject (Kothari, 2004). This design was therefore considered useful in investigating the influence of mathematics braille proficiency on mathematics performance of LWVI. The study was conducted at Kibos in Kisumu and St. Lucy's schools for the VI found both in Kisumu and Meru Counties, Kenya. These two schools were chosen because of their large number of learners with visual impairments and their long existence. This was appropriate when accessing a range of past performance by learners who are visually impaired. The two schools were mixed boarding schools meaning they enrolled both male and female learners. Two principals, all mathematics teachers in these two schools and learners who use braille in forms two and three were purposively selected for the study. Learners in forms 2 and 3 were selected because they were easily available compared to form one who might not have reported and form fours who would be focusing on KCSE examinations. From the target population of 2 head teachers, 34 teachers and 216 learners, the study purposively sampled 2 head teachers, 9 mathematics teachers and 44 learners to get a total of 55 respondents.

In this study, the data collection instruments were carefully chosen in a bid to respond to the nature and depth of information required. This study made use of a Braille proficiency test to determine the Braille proficiency skills acquired by learners This test was administered in Braille. There were varied questions testing on learners' ability to explore tactile graphics, write the correct mathematical symbols and read correctly the mathematical Braille notations. In addition, a questionnaire for teachers, an interview guide for the principles and an observation schedule were used to enhance data collection.

Teachers and learners were observed in their classes to establish the strategies teachers used to teach mathematics to learners with visual impairments. Interviews were conducted and recorded for further transcription and organization in themes in line with the objectives of the study. Observational and interview data were triangulated with questionnaires for teachers. Finally, past records of performance in the mathematics subject were analyzed. 


\subsection{Logistical and Ethical Considerations}

The researcher obtained a letter permitting the carrying out of this research from Kenyatta University (Graduate School). Permission to conduct the study and a research permit was also sought from the National Commission for Science, Technology and Innovation (NACOSTI) and the County Education Offices. The research participants were informed of the purpose of this study and its possible benefits before data collection. Their consent to participate in the study was sought. They were given freedom to withdraw their participation from the study at any time they wished to (Creswell, 2009; Kombo \& Tromp, 2006). The respondents filled a consent form. To ensure anonymity of participants and confidentiality of their responses, their names were represented by letters.

\subsection{Data Collection}

After the issuance of a research permit by the National Council for Science, Technology and Inovation (NACOSTI), the researcher booked appointments with the school head teachers on the day and date to visit their schools to explain the purpose of this study, when to administer Braille proficiency test to the learners. A research assistant was hired to help with data collection. A Braille proficiency test was administered to learners to test their mathematics Braille skills. This was done in a period of thirty minutes in each class.

\subsection{Data Analysis}

In this study, quantitative data were analyzed using the Statistical Package for Social Sciences (SPSS) computer program version 22. A correlation was also carried out to establish the relationship between mathematics Braille proficiency skills and mathematics performance. Qualitative data was analyzed thematically. After data analysis, the findings were reported using pie-charts, graphs and frequency tables, as well as in narrative form through participants 'voices.

\section{Findings and Discussion}

\subsection{Mathematics Braille Skills Possessed by Learners with VI}

The mathematics Braille skills possessed by learners with visual impairments were investigated. Learners with visual impairment sat for a mathematics Braille proficiency test and their scores were recorded in the table below.

Table 7: Mathematics Braille Proficiency Test Scores

\begin{tabular}{|c|c|c|}
\hline Scores (\%) & Frequency & Percent (\%) \\
\hline 0 & 6 & 18.2 \\
\hline 5 & 5 & 15.2 \\
\hline 10 & 10 & 30.3 \\
\hline 15 & 6 & 18.2 \\
\hline 20 & 1 & 3.0 \\
\hline 25 & 2 & 6.1 \\
\hline
\end{tabular}


LEARNERS WITH VISUAL IMPAIRMENT IN SELECTED SPECIAL SECONDARY SCHOOLS IN KENYA

\begin{tabular}{|c|c|c|}
\hline \hline 30 & 2 & 6.1 \\
\hline 50 & 1 & 3.0 \\
\hline Total & $\mathbf{3 3}$ & $\mathbf{1 0 0}$ \\
\hline
\end{tabular}

As the table above demonstrates, majority of the learners, 10 out of 33 , scored $10 \%, 6$ scored $0 \%, 5$ attained 5\%, 6 scored 15\%, 1 got 20\%, 2 got 25\%, 2 attained $30 \%$, and 1 attained $50 \%$ in the test. These results show that majority of the students performed below average with 30 out of 33 learners who sat for the test scoring $25 \%$ or below.

Three learners did not sit for the mathematics braille proficiency test. This may have been due to the fact that, the three feared to take on the test and therefore went into hiding for fear of performing dismally in the test. This left the researcher with only 33 respondents sitting for the proficiency test. Dread for mathematics coupled with negative attitude towards the subject is a resultant inability of learners with VI to actively engage themselves with the mathematical problems a condition that leads to their poor acquisition of braille proficiency skills. Looking at the results above, the majority of learners lack mathematics braille proficiency skills which are necessary for average or above average mathematics performance.

\subsection{Documentary Evidence of Mathematics Performance by Learners with Visual Impairments Over a Period of Two Years}

Table 8: Form One LWVI termly performance in mathematics (2017)

\begin{tabular}{|l|c|c|c|}
\hline \multirow{2}{*}{ Respondents } & \multicolumn{3}{|c|}{ Scores (\%) } \\
\cline { 2 - 4 } & Term $\mathbf{1}$ & Term 2 & Term 3 \\
\hline A & 32 & 08 & - \\
\hline B & 70 & 32 & - \\
\hline C & 77 & 20 & 55 \\
\hline D & 56 & 11 & - \\
\hline E & 26 & - & - \\
\hline F & 21 & 05 & - \\
\hline G & 27 & 03 & 10 \\
\hline H & 5 & 2 & 9 \\
\hline I & 4 & 2 & 12 \\
\hline J & 2 & 3 & 9 \\
\hline K & 7 & 2 & 14 \\
\hline L & 8 & 2 & 18 \\
\hline M & 30 & 15 & \\
\hline
\end{tabular}

The findings in Table 8 and Table 9 indicate a drastic change in performance in Mathematics of LWVI in Form One as compared to performance in Form Two where majority of LWVI are scoring grade E. Responses from the interview also supported the findings where a learner said: 'I declined in performance as I went higher'. 
Table 9: Form Two LWVI termly performance in mathematics (2018)

\begin{tabular}{|l|c|c|c|}
\hline \multirow{2}{*}{ Respondents } & \multicolumn{3}{|c|}{ Scores (\%) } \\
\cline { 2 - 4 } & Term 1 & Term 2 & Term 3 \\
\hline A & 02 & 01 & 01 \\
\hline B & 06 & 02 & 01 \\
\hline C & 15 & 01 & 06 \\
\hline D & 05 & 01 & 01 \\
\hline E & 11 & 01 & 06 \\
\hline F & 01 & 01 & 06 \\
\hline G & 08 & 01 & 01 \\
\hline H & 05 & 05 & 17 \\
\hline I & 24 & 21 & 20 \\
\hline J & 07 & 01 & 24 \\
\hline K & 04 & 01 & 05 \\
\hline L & 22 & 16 & 01 \\
\hline M & 08 & 01 & 01 \\
\hline N & 01 & 01 & 01 \\
\hline O & - & 09 & 20 \\
\hline P & 06 & 07 & 16 \\
\hline Q & 05 & 02 & 16 \\
\hline R & 08 & 02 & 14 \\
\hline S & 06 & 03 & 06 \\
\hline T & 07 & 03 & 11 \\
\hline U & 15 & 05 & 12 \\
\hline V & 02 & 01 & 01 \\
\hline
\end{tabular}

\subsection{Relationship between Mathematics Braille Proficiency Skills and Mathematics Performance}

As for whether there was a relationship between mathematics Braille proficiency skills and mathematics termly performance of learners with VI, a correlation analysis was conducted using Pearson correlation coefficient.

Table 10: Correlation of Braille proficiency and mathematics performance correlation matrix

\begin{tabular}{|l|l|c|c|c|c|c|c|c|}
\hline \multicolumn{2}{|c|}{} & & \multicolumn{3}{c|}{ Form one } & \multicolumn{3}{c|}{ Form two } \\
\cline { 3 - 10 } \multicolumn{2}{|c|}{} & $\begin{array}{c}\text { Braille } \\
\text { proficiency }\end{array}$ & $\begin{array}{c}\text { Term } \\
\mathbf{1}\end{array}$ & \begin{tabular}{c} 
Term \\
\multicolumn{2}{|c|}{}
\end{tabular} & $\begin{array}{c}\text { Term } \\
\mathbf{3}\end{array}$ & $\begin{array}{c}\text { Term } \\
\mathbf{1}\end{array}$ & $\begin{array}{c}\text { Term } \\
\mathbf{2}\end{array}$ & $\begin{array}{c}\text { Term } \\
\mathbf{3}\end{array}$ \\
\hline \multirow{3}{*}{$\begin{array}{l}\text { Braille } \\
\text { Proficiency }\end{array}$} & Pearson Correlation & 1 & $.846\left(^{* *}\right)$ & .591 & .810 & .363 & -.371 & -.383 \\
\cline { 2 - 10 } & Sig. (2-tailed) &. & .008 & .162 & .399 & .377 & .366 & .348 \\
\cline { 2 - 9 } & $\mathrm{N}$ & 8 & 8 & 7 & 3 & 8 & 8 & 8 \\
\hline
\end{tabular}

${ }^{* *}$ Correlation is significant at the 0.01 level (2-tailed).

The relationship between the mathematics proficient test scores and form one term 1 scores was significant $(\mathrm{r}=0.846, \mathrm{P}=0.008)$. The positive relationship showed that improved Braille proficiency indicated a better performance. A positive relationship was recorded between Braille proficiency with performance in mathematics; form 1, term 2 ( $\mathrm{r}$ $=0.591, \mathrm{P}=0.162$; form 1 , term $3(\mathrm{r}=0.810, \mathrm{P}=0.399$ and form 2 , term $1(\mathrm{r}=0.363, \mathrm{P}=377)$. However, there was insignificant relationship in Braille proficiency score and 
mathematics performance of form 2 term $2(r=-0.371, P=0.366)$ and form 2 , term $3(r=-$ 0.383, $\mathrm{P}=0.348)$.

Although there was no statistical significance in the relationship between mathematics Braille proficiency and mathematic in most of the term performance, the positive relationship were good indicators. There were many factors that contributed to the poor performance by LWVI in mathematics and so with accumulation of each factor contributing would be statistically significant. Therefore, there is importance to impart mathematics Braille skills coupled with positive attitude to learners with VI.

\section{Conclusion}

From this study, it can be concluded that learners with visual impairment had inadequate braille skills to enable them compute and solve mathematics problems as majority were not conversant with mathematics symbols. It was also clear that mathematic performance declined as LWVI progressed higher in their education. Finally, there was a positive relationship between mathematics Braille proficiency and mathematics performance. Therefore, lack of competence in mathematics Braille contributes to poor performance in mathematics.

\subsection{Recommendations}

This study recommended that KICD should ensure that curriculum on mathematics braille teaching is put in place, expanded and adhered to through organizing teacher seminars and workshops for induction. Headteachers should ensure proper mechanisms for teaching mathematics in order to promote acquisition of necessary mathematics braille skills greatly needed by learners at the secondary school level of education.

\section{Conflict of interest statement}

The authors of this paper have conflict of interest related to its content and publication.

\section{About the authors}

Mr. Martinn Obiero Okumu is a Masters student in Kenyatta University. He is a lecturer at Kenya Institute for the Blind. He heads a department known as public information services.

Dr. Margaret Murugami is a senior lecturer in the department of Early Childhood and Special Needs Education in Kenyatta University. She is a specialist in the area of visual impairment and inclusive education. She has a doctoral degree from University of South Africa with specialization in inclusive education. Margaret has taught courses in braille at undergraduate and postgraduate levels. Among her research interests are disability and identity, identity and psychological well-being and braille proficiency among students and teachers and has substantial publications in these areas.

Dr. Lubna Mazrui holds a doctorate in Special Needs Education and is currently a lecturer at Kenyatta University's Department of Early Childhood and Special Needs 
Education. As a person with a visual impairment, she is a user of Mathematics Braille code and has taught braille at undergraduate level. She also possesses knowledge on assistive technology assessments for learners with disabilities, and on training in the use and care of assistive technology products for persons with visual impairment. Among Lubna's research interests are disability rights, inclusive education, and identity and psychological wellbeing of learners with and without disabilities. She has publications in these areas.

\section{References}

Ary, D., Jacobs, L. C., Sorensen, C. \& Walkam (2010). Introduction to Research in Education (9thed), USA. Nelson education Ltd.

Borg, R. \& Gall, P. (2007). Educational research: An introduction 6th Edition; Longman Publishers, USA.

Braun, V., \& Clarke, V. (2006). Using thematic analysis in psychology. Qualitative research in psychology, 3(2), 77-101.

Bryman, A. (2001). Triangulation. Retrieved February 15, 2010.

Creswell, J. W. (2009). Research design: Qualitative and mixed methods approaches. London and Thousand Oaks: Sage Publications.

Gay, L. R., Mills, G. E., \& Airasian, P. W. (2009). Educational research: Competencies for analysis and applications. Merrill/Pearson.

Kapperman, G., \& Sticken, J. (2003). A case for increased training in the Nemeth code of braille mathematics for teachers of students who are visually impaired. Journal of Visual Impairment \& Blindness, 97(2), 110-112.

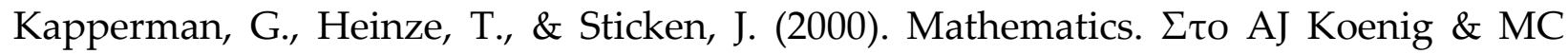
Holbrook. Foundations of education: instructional strategies for teaching children and youths with visual impairments, 370-400.

Kapperman, G., Sticken, J., \& Heinze, T. (2002). Survey of the use of assistive technology by Illinois students who are visually impaired. Journal of Visual Impairment $\mathcal{E}$ Blindness, 96(2), 106-108.

Kohanová, I. (2006). Teaching mathematics to non-sighted students: With specialization in solid geometry. Unpublished doctoral thesis). Bratislava.

Kombo, D. K., \& Tromp, D. L. (2006). Proposal and thesis writing: An introduction. Nairobi: Paulines Publications Africa, 5, 814-30.

Kothari, C. R. (2004). Research methodology, methods and techniques ( $2^{\text {nd }}$ ed. New Age International Publishers.

Mangula, A. S. (2010). Enhancing the utilization of primary mental health care services in Dodoma, Tanzania (Doctoral dissertation, Stellenbosch: University of Stellenbosch). Mang'ula, N. E. (2010). Factors affecting the performance of mathematics by girls with visual impairments at Thika high school for the blind Kenya. 
Mcmillan, J. \& Schumacher, S. (2010). Research in Education: Evidence-based Inquiry; 7th ed. Pearson USA.

Melnick, S. A., \& Meister, D. G. (2008). A comparison of beginning and experienced teachers' concerns. Educational research quarterly, 31(3), 39-56.

Mugenda, O. \& Mugenda, A. (2009). Research methods: Quantitative and qualitative approaches. Act Press, Kenya.

Mwangi, S. M. (2014). Factors that influence Braille learning in Thika Primary School for the Blind in Central Province of Kenya. Kenyatta University Library, unpublished Thesis.

Nemeth, A. (1988). Braille: The Nemeth Braille Code for Mathematics and Science Notation; the Agony and the Ecstasy. Braille Monitor: Louisville, Ky: American Printing House for the Blind.

Njue, S. N. (2009). Factors affecting Braille competency among learners with total loss of vision in Kenya, Kenyatta University library, unpublished thesis.

Nzoka, S. M. (2011). Establishing Braille proficiency levels among primary school teachers of learners who are blind in Kenya, Kenyatta University. (Doctoral dissertation).

Orodho, P. (2009). Elements of education and social science research methods; 2nd edition, Kenezja Publishers Maseno, Kenya. 
Creative Commons licensing terms

Authors will retain the copyright of their published articles agreeing that a Creative Commons Attribution 4.0 International License (CC BY 4.0) terms wil be applied to their work. Under the terms of this license, no permission is required from the author(s) or publisher for members of the community to copy, distribute, transmit or adapt the article content, providing a proper, prominent and unambiguous attribution to the authors in a manner that makes clear that the materials are being reused under permission of a Creative Commons License. Views, opinions and conclusions expressed in this research article are views, opinions and conclusions of the author(s). Open Access Publishing Group and European Journal of Special Education Research shall not be responsible or answerable for any loss, damage or liability caused in relation to/arising out of conflict of interests, copyright violations and inappropriate or inaccurate use of any kind content related or integrated on the research work. All the published works are meeting the Open Access Publishing requirements and can be freely accessed, shared, modified, distributed and used in educational, commercial and non-commercial purposes under a Creative Commons Attribution 4.0 International License (CC BY 4.0). 